\title{
MicroRNA-24 can control triacylglycerol synthesis in goat mammary epithelial cells by targeting the fatty acid synthase gene
}

\author{
H. Wang, ${ }^{*}$ J. Luo, ${ }^{* 1}$ Z. Chen, ${ }^{*}$ W.T. Cao, ${ }^{*}$ H. F. Xu, ${ }^{*}$ D. M. Gou, $†$ and J. J. Zhu* \\ *Shaanxi Key Laboratory of Molecular Biology for Agriculture, College of Animal Science and Technology, Northwest A\&F University, Yangling, \\ Shaanxi 712100, P.R. China \\ †Shenzhen Key Laboratory of Microbial Genetic Engineering, College of Life Sciences, Shenzhen University, Guangdong 518060, P.R. China
}

\section{ABSTRACT}

In nonruminants it has been demonstrated that microRNA-24 (miR-24) is involved in preadipocyte differentiation, hepatic lipid, and plasma triacylglycerol synthesis. However, its role in ruminant mammary gland remains unclear. In this study we measured miR-24 expression in goat mammary gland tissue at 4 different stages of lactation and observed that it had highest expression at peak lactation when compared with the dry period. Overexpression or downregulation of miR-24 in goat mammary epithelial cells (GMEC) strongly affected fatty acid profiles; in particular, miR-24 enhanced unsaturated fatty acid concentration. Additional effects of miR-24 included changes in triacylglycerol content and the expression of fatty acid synthase, sterol regulatory element binding transcription protein 1, stearoylCoA desaturase, glycerol-3-phosphate acyltransferase mitochondrial, and acetyl-CoA carboxylase. Luciferase reporter assay confirmed that fatty acid synthase is a target of miR-24. Taken together, these results not only highlight the physiological importance of miR-24 in fatty acid metabolism in GMEC, but also laid the foundation for further research on regulatory mechanisms among miR-24 and other microRNA expressed in GMEC.

Key words: microRNA-24, milk fat metabolism, fatty acid synthase

\section{INTRODUCTION}

The mammary glands are specialized organs whose main function is to produce milk, the primary source of nutrition for neonates. Compared with cow milk, goat milk contains higher levels of fat and long-chain FA (Juarez and Ramos, 1986). Milk fat secreted from mammary epithelial cells is in the form of lipid droplets,

Received February 4, 2015.

Accepted July 25, 2015.

${ }^{1}$ Corresponding author: luojun@nwsuaf.edu.cn which are almost completely composed of triacylglycerol (TAG; Hansen et al., 1984; Bionaz and Loor, 2008). A network of genes with complementary functions coordinates the overall process of ruminant milk fat synthesis, which encompasses de novo synthesis (lipogenesis, FA uptake and transport, TAG synthesis, and lipid droplet formation; Bionaz and Loor, 2008).

MicroRNA (miRNA) are a subclass of noncoding RNA that direct mRNA degradation or disrupt its translation in a sequence-dependent manner (Bartel, 2004). They play an important role in various biological processes, for instance tissue development (Yang et al., 2015), cell differentiation (Gay et al., 2014; Vimalraj and Selvamurugan, 2014), cell proliferation and apoptosis (Chen et al., 2010; Adlakha and Saini, 2011), as well as cellular lipid metabolism (Fernández-Hernando et al., 2011; Shirasaki et al., 2013).

Recent studies have revealed the importance of certain miRNA as key regulators in lactating mammary gland of several species (Gu et al., 2007; Wang et al., 2012). For instance, it has been demonstrated that miR-103 can increase milk fat synthesis by enhancing TAG accumulation and lipid droplet formation in goat mammary epithelial cells (GMEC; Lin et al., 2013b). Likewise, miR-27a can decrease mRNA expression of genes associated with TAG synthesis by suppressing peroxisome proliferator-activated receptor gamma (PPARG) protein levels in GMEC (Lin et al., 2013a).

Besides the key role of miR-103 and miR-27a in GMEC, recent data utilizing mice revealed that miR24 enhanced hepatic lipid accumulation by inhibiting expression of insulin induced gene 1 (INSIG1; $\mathrm{Ng}$ et al., 2014) and also by regulating 3T3-L1 preadipocyte differentiation (Kang et al., 2013). Comparative miRNA profiling of goat mammary gland tissue revealed that the expression of miR-24 differs between the peaklactation and the dry period (Li et al., 2012a). Thus, these combined data led us to hypothesize that miR-24 may also play a role in the regulation of FA metabolism in GMEC. Specific objectives were to evaluate the functional relevance of miR-24 in milk fat synthesis via treatment of GMEC with a miR-24 mimic or inhibitor 
coupled with FA profiling, lipid droplet content, and lipogenic mRNA expression analyses.

\section{MATERIALS AND METHODS}

\section{Tissue Samples}

Thirty-nine healthy second-lactation Xinong Saanen goats (3 yr old) of similar weight were selected from the Northwest A\&F University herd. Twenty-four goats in mid lactation (120 d after parturition) and 5 goats in early lactation (15 d after parturition), peak lactation (60 d after parturition), and the dry period (60 $\mathrm{d}$ before parturition) were euthanized and mammary gland tissue samples were collected. Total RNA was isolated from each tissue sample using Trizol reagent (Invitrogen, Waltham, MA) according to the manufacturer's instructions. The RNA quality and quantity were determined using an Agilent 2100 bioanalyzer (Agilent Technologies, Palo Alto, CA). The peak lactation tissue samples also were used for cell culture as described below.

\section{Cell Culture and Transfection}

The GMEC were isolated and cultured according to published protocols (Wang et al., 2010; Shi et al., 2013b, 2014). Briefly, the mammary tissue was cultured for 4 to $7 \mathrm{~d}$ until cells were detached. The fibroblast-like cells and adipocytes were selected out after 5 passages and purification. The passage of 8 to 12 GMEC were cultured to confluence in a basal DMEM/ F12 medium (Invitrogen) supplemented with insulin (5 $\mathrm{\mu g} / \mathrm{mL}$; Sigma-Aldrich, St. Louis, MO), penicillin and streptomycin $(100 \mathrm{U} / \mathrm{mL}$; Harbin Pharmaceutical Group, Harbin, China), epidermal growth factor 1 (10 $\mathrm{ng} / \mathrm{mL}$; Invitrogen), hydrocortisone $(1 \mu \mathrm{g} / \mathrm{mL}$; SigmaAldrich), and $10 \%$ fetal bovine serum (Hyclone, Logan, $\mathrm{UT})$ at $37^{\circ} \mathrm{C}$ in a humidified atmosphere with $5 \% \mathrm{CO}_{2}$. To induce lactogenesis, GMEC were cultured in a lactogenic medium for $48 \mathrm{~h}$ before initial experiments, as reported previously (Peterson et al., 2004; Kadegowda et al., 2009). The lactogenic medium was prepared as the basal medium supplemented with prolactin $(2 \mu \mathrm{g} /$ $\mathrm{mL}$; Sigma-Aldrich).

The GMEC were plated before transfection at a density of $2.5 \times 10^{5}$ cells in 6 -well plates, and these were used for quantitative real-time PCR (RT-qPCR), oil red $\mathrm{O}$, and FA synthase activity experiments. For Western blot, FA extraction, and cellular TAG content assays, cells were plated at a density of $1 \times 10^{6}$ cells in 60-mm dishes. The luciferase reporter experiments were performed with GMEC at a density of 50,000 cells in 48well plates. Cells were transfected with a miR-24 mimic $(60 \mathrm{n} M)$, inhibitor $(60 \mathrm{n} M)$, and the respective controls (60 nM; Invitrogen) using Lipofectamine RNAiMAX (Invitrogen) according to the manufacturer's instructions. Cells were harvested $48 \mathrm{~h}$ after transfection.

The miRNA mimic is a small chemically modified double- or single-stranded RNA molecule designed to mimic mature endogenous miRNA after transfected into cells, whereas a miRNA inhibitor is a single-stranded RNA molecule designed to specifically bind to and inhibit endogenous miRNA molecules. We designed a double-stranded RNA molecule as a miR-24 mimic and a single-stranded RNA molecule as a miR-24 inhibitor. The negative control for the mimic treatment was double-stranded and the inhibitor (miRNA inhibitor negative control) was single-stranded. The sequences of mimic, inhibitor, and controls are listed in Table 1.

\section{RT-qPCR and Western Blot}

Total RNA was extracted from cultured cells with Trizol reagent (Invitrogen) according to the manufacturer's instructions. The mature miRNA expression level was determined with S-Poly $(\mathrm{T})$ assay (Kang et al., 2012). Briefly, a $10-\mu \mathrm{L}$ reaction included $0.2 \mu \mathrm{g}$ of total RNA, $2.5 \mu \mathrm{L}$ of $4 \times$ reaction buffer, $1 \mu \mathrm{L}$ of polyA/reverse transcriptase enzyme mix, and $1 \mu \mathrm{L}$ of $0.5 \mu M$ reverse transcription $(\mathbf{R T})$ primer. The reaction was performed at $37^{\circ} \mathrm{C}$ for $30 \mathrm{~min}$, followed by $42^{\circ} \mathrm{C}$ for $30 \mathrm{~min}$, and subsequently at $75^{\circ} \mathrm{C}$ for $5 \mathrm{~min}$. The RT products were amplified and detected with

Table 1. The sequences of microRNA-24 (miR-24) mimic, inhibitor, and controls

\begin{tabular}{ll}
\hline Name & Sequence $\left(5^{\prime}-3^{\prime}\right)$ \\
\hline MiR-24 mimic & Sense: 5 '-UGGCUCAGUUCAGCAGGAACAG-3' \\
Negative control (NC) & Antisense: 5'-GUUCCUGCUGAACUGAGCCAUU-3' \\
& Sense: 5'-UUCUCCGAACGUGUCACGUTT-3' \\
MiR-24 inhibitor & Antisense: 5'-ACGUGACACGUUCGGAGAATT-3' \\
MicroRNA inhibitor NC & Sense: 5'-CUGUUCCUGCUGAACUGAGCCA-3' \\
\hline
\end{tabular}


Table 2. Characteristics of primers in the microRNA (miRNA) quantitative real-time PCR

\begin{tabular}{ll}
\hline MiRNA & Sequence $\left(5^{\prime}-3^{\prime}\right)$ \\
\hline MiR-24 & Reverse (R): 5'-GTGCAGGGTCCGAGGTCAGAGCCACCTGGGCAATTTTTTTTTTTGTTCCT-3' \\
& Forward (F): 5'-TTCGGTGGCTCAGTTCAGC-3' \\
MiR-27a & R: 5'-GTGCAGGGTCCGAGGTCAGAGCCACCTGGGCAATTTTTTTTTTTGCGGAA-3' \\
& F: 5'-TTCGGTTCACAGTGGCTAAG-3' \\
MiR-103 & R: 5'-GTGCAGGGTCCGAGGTCAGAGCCACCTGGGCAATTTTTTTTTTTCATAGC-3' \\
& F: 5'-GGAGCAGCATTGTACAGGG-3' \\
5S rRNA & R: 5'-GTGCAGGGTCCGAGGTCAGAGCCACCTGGGCAAAAGCCTACAGCACCCG-3' \\
Universal reverse primer & F: 5'-TCTCAGAAGCTAAACAGGGTCG-3' \\
\hline
\end{tabular}

an universal Taqman probe (IDT, Coralville, IA) in a $20-\mu \mathrm{L}$ PCR reaction that contained $0.3 \mu \mathrm{L}$ of RT products, $4 \mu \mathrm{L}$ of $5 \times$ qPCR probe Mix, $0.5 \mathrm{U}$ of GoTaq Hot Start Polymerase (Promega, Madison, WI), $0.2 \mathrm{mM}$ universal Taqman probe, and $0.5 \mu M$ forward primer and universal reverse primer, respectively. The PCR reaction was performed at $95^{\circ} \mathrm{C}$ for $30 \mathrm{~s}$, followed by 40 cycles of $95^{\circ} \mathrm{C}$ for $10 \mathrm{~s}$ and $60^{\circ} \mathrm{C}$ for $30 \mathrm{~s}$. The $5 \mathrm{~S}$ rRNA was used as an internal control. All the primers used for miRNA real-time quantitative PCR (RT-qPCR) are listed in Table 2.

For mRNA, $0.5 \mu \mathrm{g}$ of total RNA was used to synthesize cDNA using the PrimeScript RT Reagent Kit with gDNA Eraser (Perfect Real Time, Takara, Shiga, Japan). The RT-qPCR assays were performed according to the manufacturer's instructions (SYBR Premix Ex TaqII, Perfect Real Time, Takara). Specific primers were designed for several target genes: fatty acid synthase $(F A S N)$, acetyl-CoA carboxylase $\alpha(A C A C A)$, and acyl-CoA synthase short-chain family member 2 (ACSS2) play a key role in de novo FA synthesis (Bionaz and Loor, 2008); stearoyl-CoA desaturase 1 (SCD1), glycerol-3-phosphate acyltransferase mitochondrial (GPAM), 1-acylglycerol-3-phosphate O-acyltransferase 6 (AGPAT6), and lipin 1 (LPIN1) are involved in desaturation and TAG synthesis (Coleman, 2004); perilipin 2 (PLIN2) and patatin-like-phospholipase domain containing 2 (PNPLA2) are important in lipid droplet formation; lipoprotein lipase $(L P L)$ hydrolyzes circulating TAG and the FA released are transported into cells by thrombospondin receptor $(C D 36)$ and fatty acid-binding protein 4 (FABP4). In addition, PPARG, sterol regulatory element binding transcription factor 1 (SREBF1), and INSIG1 are key transcription regulators controlling the expression of genes related to FA and TAG synthesis (Bionaz and Loor, 2008). All the primers used for mRNA RT-qPCR are listed in Table 3 . The mRNA expression was normalized using the geometric mean (Bionaz and Loor, 2008) of the 3 internal controls (ubiquitously expressed transcript, mitochondrial ribosomal protein L39, and ribosomal protein S9;
Bionaz and Loor, 2007; Kadegowda et al., 2009; Bonnet et al., 2013). All reactions, including controls without template, were carried out on a Bio-Rad CFX96 realtime PCR detection system (Bio-Rad, Hercules, CA). After amplification, the products were confirmed by agarose gel electrophoresis and sequencing.

For Western blot, cells were collected and lysed in RIPA buffer (Solarbio, Beijing, China) supplemented with PMSF (Pierce, Rockford, IL). Proteins were separated by SDS-PAGE, transferred to nitrocellulose membrane (Millipore, Billerica, MA), and probed with the primary antibodies polyclonal rabbit anti- $F A S N$ (s1498R, 1:500; Bioss Inc., Woburn, MA) and monoclonal mouse anti-GAPDH (CWBIO, Beijing, China; 1:1000). Polyclonal goat anti-rabbit horseradish peroxidaseconjugated IgG (Tiagen, Beijing, China; 1:1000) and polyclonal goat anti-mouse HRP-conjugated IgG (Tiagen; 1:1000) were used as secondary antibody. Signals were detected by the chemiluminescent ECL Western blot detection system (Pierce).

\section{Oil Red O Staining}

The GMEC transfected with miR-24 mimic and inhibitor were washed 3 times in PBS, fixed in 10\% (vol/ vol) paraformaldehyde for $1 \mathrm{~h}$, and then washed again with PBS. The lipid droplets in the cells were stained with $5 \%$ oil red $\mathrm{O}$ in isopropanol for $20 \mathrm{~min}$ and then washed with PBS and examined microscopically.

\section{Cellular TAG Content Assay}

Cellular TAG assays were performed as previously described (Bartholomew et al., 2012; Kang et al., 2015). Briefly, GMEC were transfected with miR-24 mimic, inhibitor, and respective controls for $48 \mathrm{~h}$ and then cells were harvested in lysis buffer $(50 \mathrm{~m} M$ Tris-HCl, $\mathrm{pH}$ 7.4; $150 \mathrm{~m} M \mathrm{NaCl}, 1 \%$ Triton X-100; Amresco, Solon, $\mathrm{OH})$. A TAG colorimetric assay kit was used according to the manufacturer's instructions (Cayman Chemical, Ann Arbor, MI) on an XD 811G Biochemistry Ana- 
Table 3. Characteristics of primers in the quantitative real-time PCR

\begin{tabular}{|c|c|c|c|}
\hline $\begin{array}{l}\text { Gene and accession } \\
\text { number }^{1}\end{array}$ & $\operatorname{Primer}^{2}\left(5^{\prime}-3^{\prime}\right)$ & Efficiency $^{3}$ & Source \\
\hline FASN & F: GGGCTCCACCACCGTGTTCCA & 2.13 & Shi et al. (2013a) \\
\hline DQ915966.3 & R: GCTCTGCTGGGCCTGCAGCTG & & \\
\hline JN236219.1 & R: GGGGAATCACAGAAGCAGCC & & \\
\hline ACSS2 & F: GGCGAATGCCTCTACTGCTT & 2.08 & Bionaz and Loor (2008) \\
\hline BC134532 & R: GGCCAATCTTTTCTCTAATCTGCTT & & \\
\hline JI861797.1 & R: AAACTGTGGCTCCAATTTCGA & & \\
\hline LPIN1 & F: TCCCTGCTCGGACGTAATTG & 2.15 & Lin et al. (2013c) \\
\hline NM_00120615.1 & R: TGGCCACCAGAATAAAGCATG & & \\
\hline PLIN2 & F: TACGATGATACAGATGAATCCCAC & 2.16 & Shi et al. (2013a) \\
\hline HQ846826 & R: CAGCATTGCGAAGCACAGAGT & & \\
\hline$L P L$ & F: AGGACACTTGCCACCTCATTC & 2.18 & Shi et al. (2013a) \\
\hline$S C D$ & F: CCATCGCCTGTGGAGTCAC & 2.10 & Shi et al. (2013a) \\
\hline GU947654 & R: GTCGGATAAATCTAGCGTAGCA & & \\
\hline INSIG1 & F: AGCCTCACAAGTTCAAGCG & 2.03 & This article \\
\hline JQ665439.1 & R: ACAGTGCTGCTAATGTCAAGG & & \\
\hline PNPLA2 & F: GGAGCTTATCCAGGCCAATG & 2.04 & Lin et al. (2013a) \\
\hline GQ918145 & R: GCGGGCAGATGTCACTCT & & \\
\hline$S R E B F 1$ & F: CTGCTGACCGACATAGAAGACAT & 2.20 & Shi et al. (2013a) \\
\hline HM443643.1 & R: GTAGGGCGGGTCAAACAGG & & \\
\hline$P P A R G$ & F: CCTTCACCACCGTTGACTTCT & 2.21 & Shi et al. (2013a) \\
\hline HQ589347.1 & R: GATACAGGCTCCACTTTGATTGC & & \\
\hline$U X T$ & F: TGTGGCCCTTGGATATGGTT & 2.10 & Bionaz and Loor (2007) \\
\hline BQ676558 & R: GGTTGTCGCTGAGCTCTGTG & & \\
\hline MRPL39 & F: AGGTTCTCTTTTGTTGGCATCC & 2.13 & Bionaz and Loor (2007) \\
\hline NM017446 & R: TTGGTCAGAGCCCCAGAAGT & & \\
\hline
\end{tabular}

${ }^{1} F A S N=$ fatty acid synthase; $A C A C A=$ acetyl-CoA carboxylase $\alpha ; A C S S 2=$ acyl-CoA synthase short-chain family member $2 ; G P A M=$ glycerol-3-phosphate acyltransferase mitochondrial; $A G P A T 6=1$-acylglycerol-3-phosphate O-acyltransferase $6 ; L P I N 1=$ lipin $1 ; S C D 1=$ stearoyl-CoA desaturase 1; PLIN2 = perilipin 2; PNPLA2 = patatin-like-phospholipase domain containing 2; $L P L=$ lipoprotein lipase; $F A B P 4$ $=$ fatty acid binding protein $4 ; C D 36=$ thrombospondin receptor; SREBF1 = sterol regulatory element binding transcription factor $1 ;$ INSIG1 $=$ insulin induced gene 1; PPARG = peroxisome proliferator-activated receptor gamma; $U X T=$ ubiquitously expressed transcript; $M R P L 39=$ mitochondrial ribosomal protein L39; RPS9 = ribosomal protein S9.

${ }^{2} \mathrm{~F}=$ forward primer; $\mathrm{R}=$ reverse primer.

${ }^{3}$ The PCR efficiency was determined by $\left[10^{(-1 / \text { slope })}\right.$; the slope was obtained by the 7 -point standard curve (with a minimum $\mathrm{R}^{2}$ of 0.99 ).

lyzer (Shanghai Odin Science \&Technology Company, Shanghai, China). Total protein was measured with the BCA protein assay kit according to the manufacturer's instructions (Thermo-Fisher Scientific, Waltham, MA) using an Agilent 2100 bioanalyzer (Agilent Technologies). The values obtained were normalized to the total cellular protein content and were expressed as micrograms per milligram of protein.

\section{Cellular FASN Activity Assay}

The enzyme activity of cellular FASN was analyzed as previously described (Chuang et al., 2011). Briefly, cells in 6-well plates were washed with cold PBS and collected. Ultrasonic disruption was achieved in assay buffer with $0.6 \mathrm{~m} M$ PMSF (Pierce) on ice and then centrifuged at $18000 \times g$ for $30 \mathrm{~min}$ at $4^{\circ} \mathrm{C}$. The assay buffer contained a $100 \mathrm{~m} M$ potassium phosphate buffer, $1 \mathrm{~m} M$ EDTA (Sigma-Aldrich), and $1 \mathrm{~m} M$ dithiothreitol (Sigma-Aldrich) at $\mathrm{pH}$ 7. The supernatant was used to evaluate the FASN activity at $340 \mathrm{~nm}$ (before and after malonyl-CoA). The assay solution without malonylCoA served as a background for the assay.

\section{Luciferase Reporter Assay}

To generate reporter constructs for luciferase assays, a 715-bp segment containing predicted miRNA target 
site in the $3^{\prime}$ untranslated regions (UTR) of FASN was cloned into the psiCHECK-2 vector (Promega) between the XhoI and NotI sites immediately downstream of the Renilla luciferase gene. The forward primer was $5^{\prime}$-ccgctcgagACAATCTGTCCCAGGTGTGCGAT-3' and the reverse primer was 5 '-taagaatgcggccgcCCAGAGCGAACGAAGGATTT-3'; the lowercase nucleotides of primers were added with restriction sites XhoI or NotI. To generate reporter constructs with mutant $3^{\prime} \mathrm{UTR}$ of $F A S N$, primers were designed for overlap PCR as follows: forward primer: 5'-GAAGAGTCGGggtgtCCGC-3'; reverse primer: 5'-TAGCGGacaccCCGACTCT-3' (the lower-case nucleotides of primers were mutant for the miR-24 target site). Five nucleotides (CTGAG) in the target site that were complementary to the miR-24

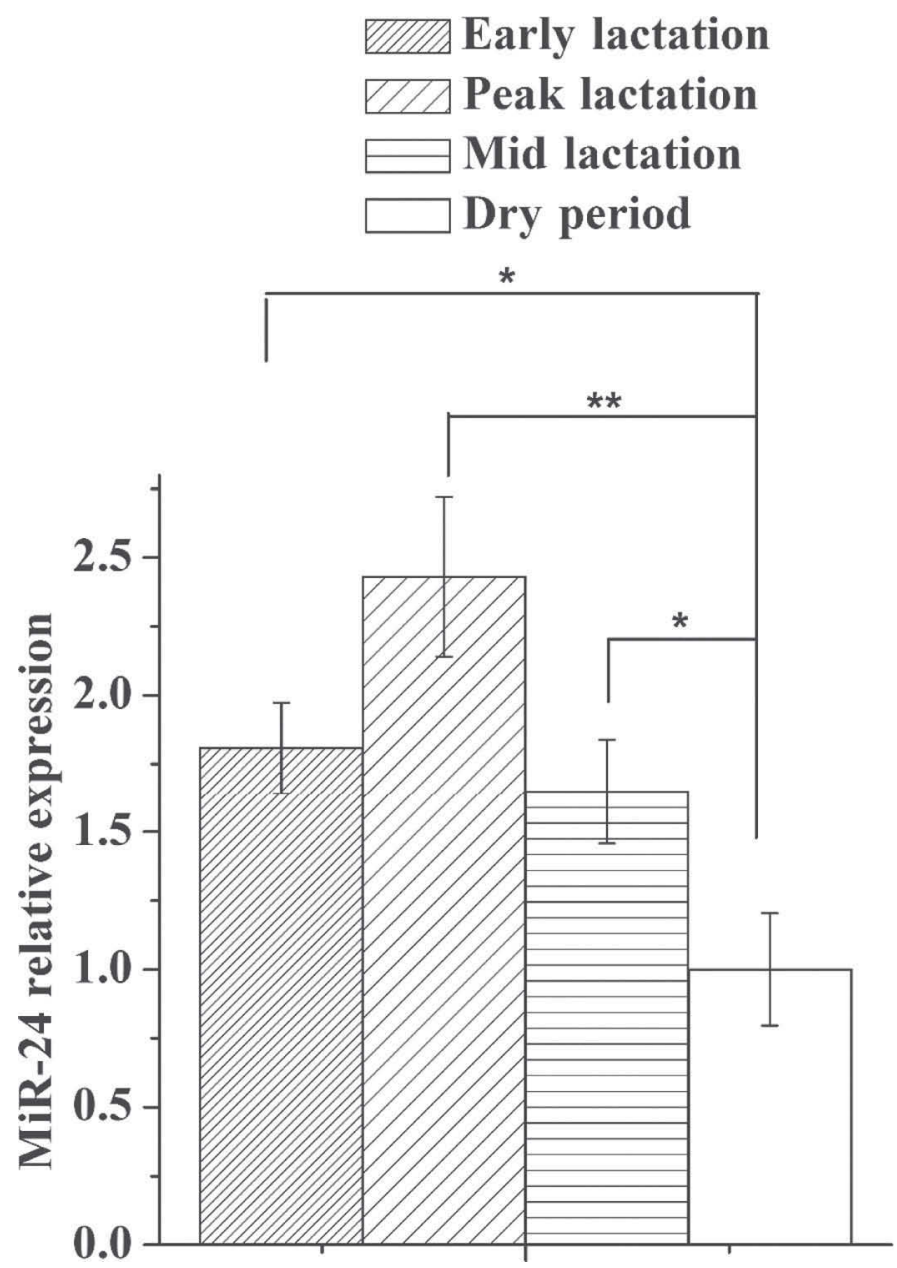

Figure 1. MicroRNA-24 (MiR-24) expression in dairy goat mammary gland tissue. All experiments were performed in quintuplicate and repeated 3 times $(\mathrm{n}=15)$. The expression of $5 \mathrm{~S}$ rRNA was used as a normalization control. Values are presented as means $\pm \mathrm{SEM} ;{ }^{*} P$ $<0.05,{ }^{* *} P<0.01$. seed region were mutated to (GGTGT). All constructs were confirmed by sequencing.

The GMEC were seeded in 48-well plates at a density of 50,000 cells per well $1 \mathrm{~d}$ before transfection. A total of $0.33 \mu \mathrm{g}$ of each reporter construct were transiently transfected using the X-tremeGENE HP DNA Transfection Reagent (Roche, Basel, Switzerland) according to the manufacturer's protocols. After a 6-h recovery period in medium, cells were transfected with miR-24 mimic $(60 \mathrm{n} M)$, inhibitor $(60 \mathrm{n} M)$, and respective controls $(60 \mathrm{n} M)$ using Lipofectamine RNAiMAX (Invitrogen) according to the manufacturer's protocols. At 48 $\mathrm{h}$ posttransfection, firefly $\left(h l u c^{+}\right)$and Renilla (hRluc) luciferase activities were measured with the Dual-Glo luciferase assay system according to the manufacturer's instructions (Promega) by a Varioskan flash (ThermoFisher Scientific); the hluc ${ }^{+}$gene was used as reference gene to correct the variation of transfection efficiency and the relative luciferase activity was calculated as hRluc/hluc ${ }^{+}$.

\section{FA Extraction and Analysis}

Extraction and analyses of FA was according to published methods (Shi et al., 2013b; Zhu et al., 2014). Briefly, total FA were extracted and methylated from approximately $100 \mathrm{mg}$ of cells using $2 \mathrm{~mL}$ of vitriol or methanol (2.5:1 vol/vol). Methylated samples were analyzed using GC-MS with an HP-5 column (Agilent Technologies). A $2-\mu \mathrm{L}$ sample at a 1:10 split ratio was injected and held for $2 \mathrm{~min}$ at $40^{\circ} \mathrm{C}$, then the temperature was increased to $240^{\circ} \mathrm{C}$ for $15 \mathrm{~min}$ at a rate of $8^{\circ} \mathrm{C} / \mathrm{min}$. For analysis, the temperature of the injector and detector was 250 and $280^{\circ} \mathrm{C}$, respectively, and the ionization energy was $70 \mathrm{eV}$ with 35 to $500 \mathrm{amu}$ mass number. Helium was the carrier gas $(0.8 \mathrm{~mL} / \mathrm{min})$.

\section{Statistical Analysis}

Data of qPCR was analyzed relative to the control using the $2^{-\Delta \Delta \mathrm{Ct}}$ method, where $\mathrm{Ct}$ is the cycle threshold. The Western blot results were quantified after normalization with GAPDH. The data for each FA was analyzed as a proportion of the total FA. The SPSS 19.0 software (IBM Corp., Armonk, NY) was used for statistical analysis. Data were analyzed by ANOVA using the general linear model procedure and mean separation was performed via Tukey; Pearson analysis was performed to identify the correlation coefficient and intensity scatter plot shows comparison of 2 miRNA profiles in mammary gland. Results are expressed as mean \pm standard error of the means. Differences were considered statistically significant at $P<0.05$. 


\section{RESULTS}

\section{miR-24 Expression Level at Different Stages of Lactation}

MicroRNA-24 was detected at all stages of lactation in whole mammary gland tissue. Relative to the dry period, the expression level of miR-24 in early, peak, and mid lactation was increased by $1.80(P<0.05)$,
$2.43(P<0.01)$, and 1.65 fold $(P<0.05)$, respectively (Figure 1).

\section{miR-24 Increases TAG Level and Milk Fat Droplet Accumulation in GMEC}

The level of miR-24 in cells transfected with miR24 mimic was over 40 times higher than the negative
A

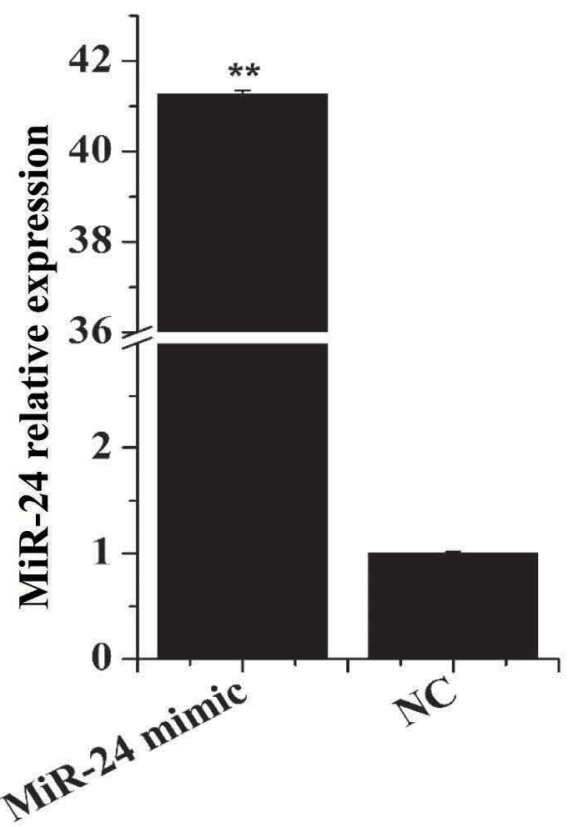

C

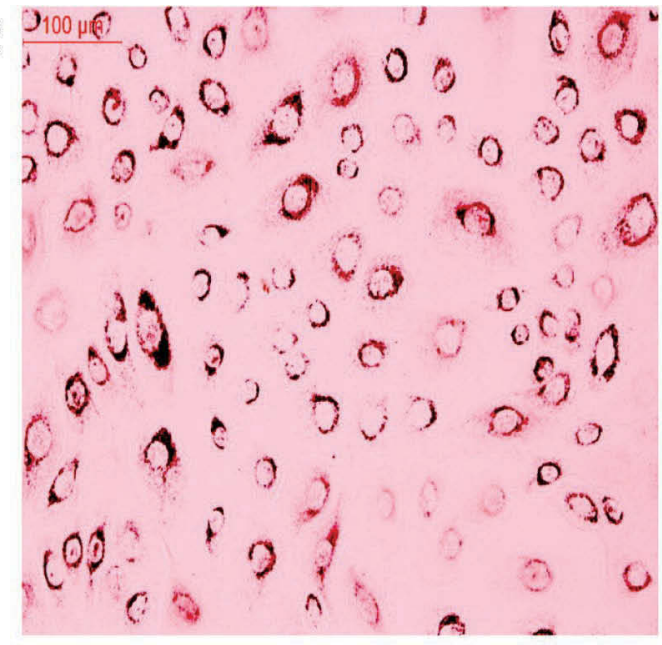

MiR-24 mimic
B
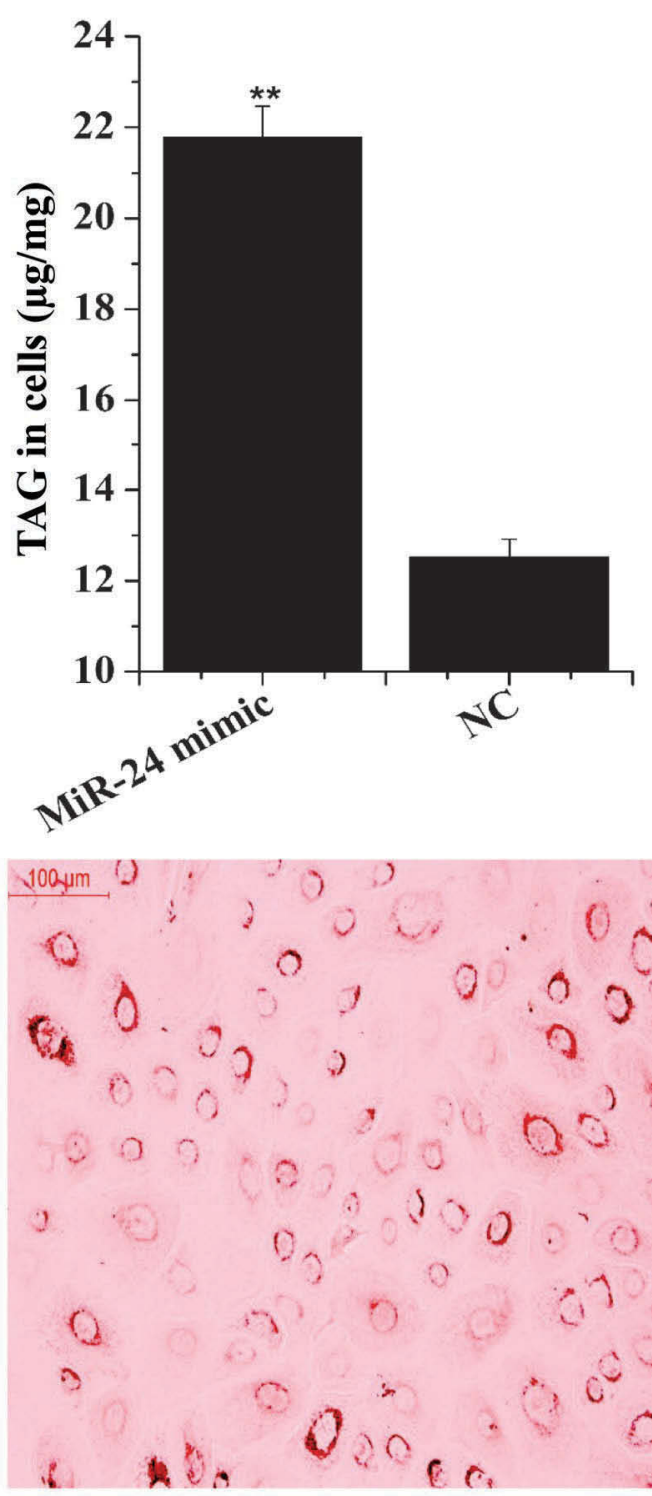

$\mathrm{NC}$

Figure 2. Changes in triacylglycerol (TAG) and lipid content in goat mammary epithelial cells caused by microRNA-24 (miR-24) mimic (60 $\mathrm{n} M)$ and miR-24 inhibitor $(60 \mathrm{n} M)$. The TAG level and lipid droplet were measured at $48 \mathrm{~h}$ post-transfection. (A and D) MiR-24 expression after treatment; (B and E) cellular TAG; $(\mathrm{C}$ and F) lipid droplet after oil red $\mathrm{O}$ treatment (one representative view); scale bar $=100 \mu \mathrm{m}$. $(\mathrm{A}$ to C) MiR-24 mimic treatment; (D to F) miR-24 inhibitor treatment. The experiments of miR-24 expression were performed in sextuplicate and repeated 3 times $(\mathrm{n}=18)$, and the other experiments were performed in duplicate and repeated 3 times $(\mathrm{n}=6)$. Values are presented as means $\pm \mathrm{SEM} ;{ }^{*} P<0.05,{ }^{* *} P<0.01$. Color version available online. 
control (Figure 2A). For the inhibition experiments, use of the miR-24 inhibitor resulted in more than a $90 \%$ decrease in miR-24 (Figure 2D).

As depicted in Figure 2B and 2C, both TAG level and lipid droplets content increased in GMEC transfected with miR-24 mimic. The TAG content of cells transfected with miR-24 mimic was increased by 1.74 fold $(P<0.05)$ compared with the negative control. We detected an accumulation of lipid droplets using oil red $\mathrm{O}$ staining after ectopic overexpression of miR24 compared with the negative control. In addition, TAG and lipid droplets content decreased in the miR24 knockdown group when compared with the control (Figure $2 \mathrm{E}$ and $2 \mathrm{~F}$ ).

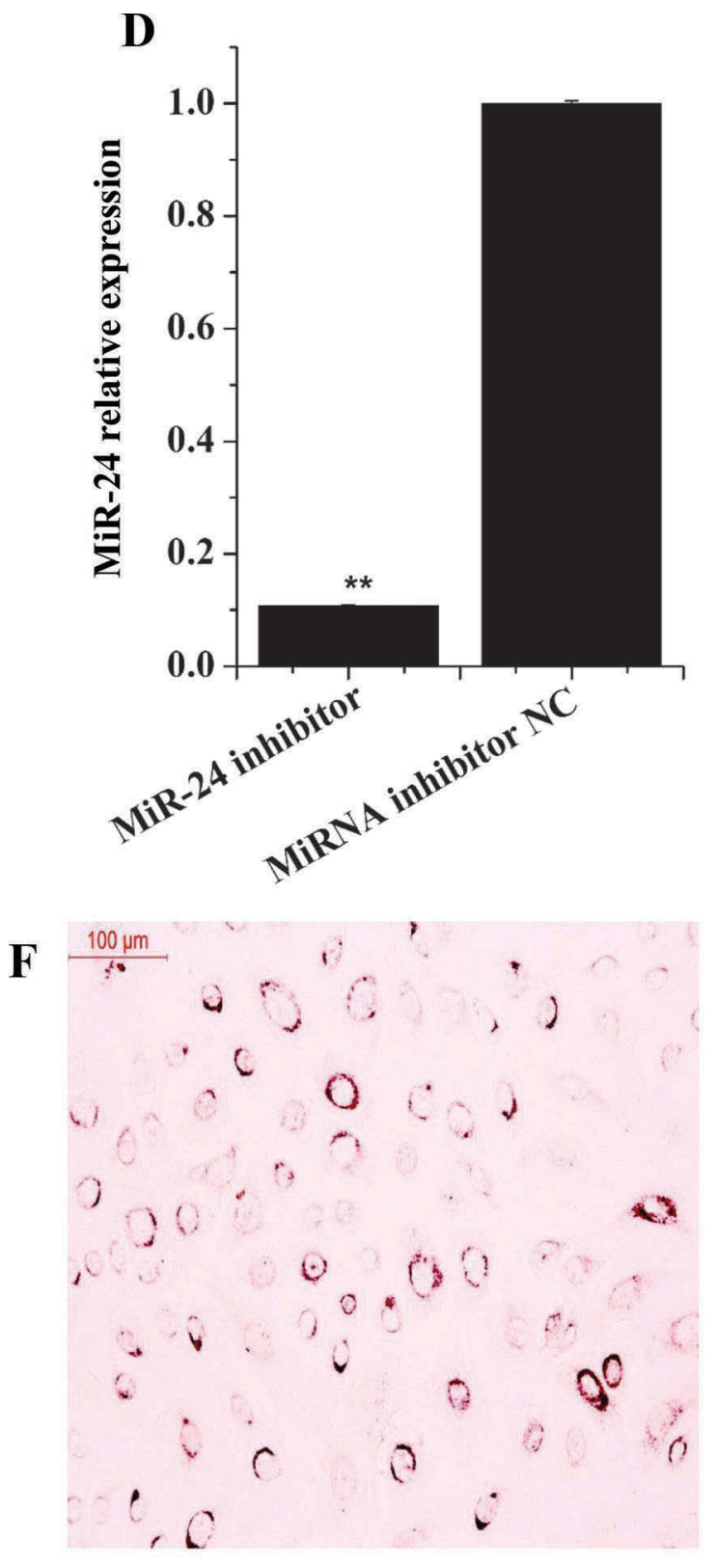

MiR-24 inhibitor
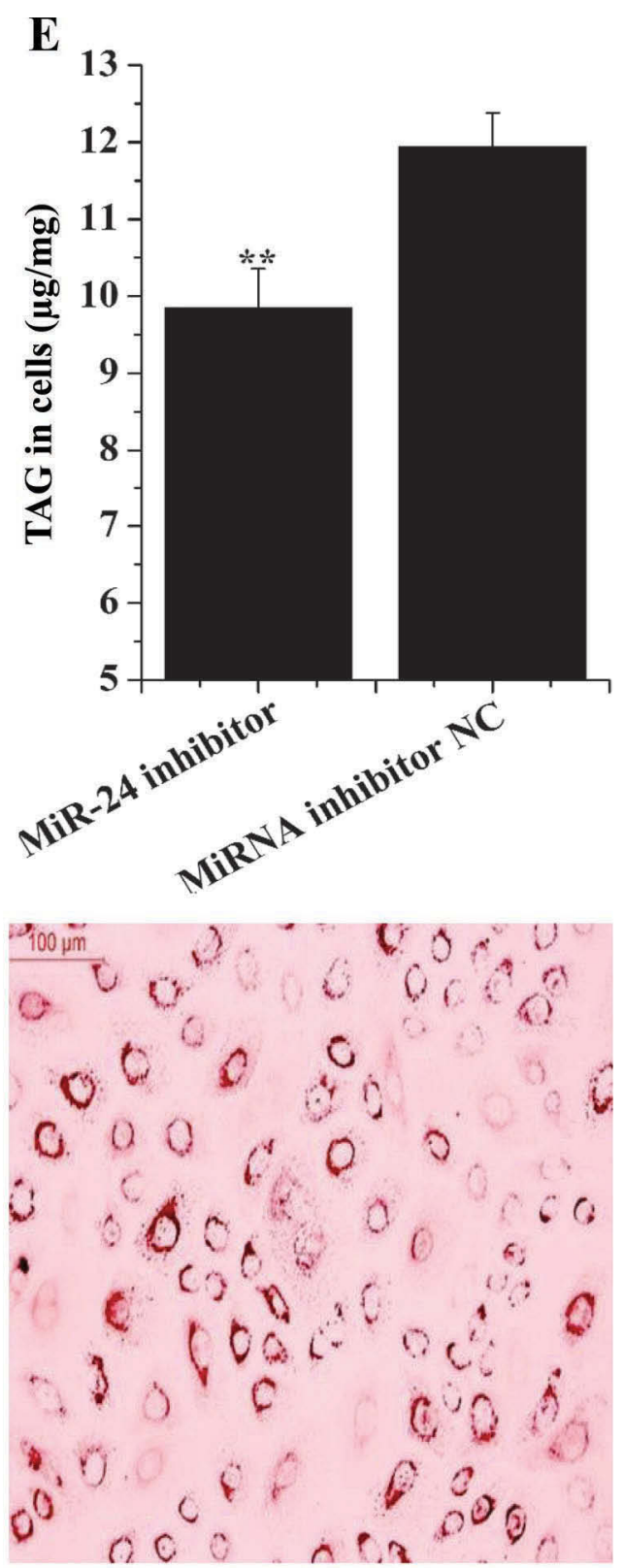

MiRNA inhibitor NC

Figure 2 (Continued). Changes in triacylglycerol (TAG) and lipid content in goat mammary epithelial cells caused by microRNA-24 (miR-24) mimic $(60 \mathrm{nM})$ and miR-24 inhibitor $(60 \mathrm{nM})$. The TAG level and lipid droplet were measured at $48 \mathrm{~h}$ post-transfection. (A and D) MiR-24 expression after treatment; (B and E) cellular TAG; (C and F) lipid droplet after oil red $\mathrm{O}$ treatment (one representative view); scale $\mathrm{bar}=100 \mu \mathrm{m}$. (A to C) MiR-24 mimic treatment; (D to F) miR-24 inhibitor treatment. The experiments of miR-24 expression were performed in sextuplicate and repeated 3 times $(\mathrm{n}=18)$, and the other experiments were performed in duplicate and repeated 3 times $(\mathrm{n}=6)$. Values are presented as means $\pm \mathrm{SEM} ;{ }^{*} P<0.05,{ }^{* *} P<0.01$. Color version available online. 


\section{miR-24 Increases the Percentage of Unsaturated FA in GMEC}

Compared with the control, miR-24 mimic had a significant positive effect on unsaturated FA and resulted in increases of palmitoleate (C16:1), oleate (C18:1), and linoleate $(\mathrm{C} 18: 2)$ by $7.22,9.52$, and $0.76 \%$, respectively, relative to the control (Table 4). In contrast, the miR-24 inhibitor had a marked negative effect on C16:1 $(P<0.05)$ and $\mathrm{C} 18: 2(P<0.05)$. The SFA palmitate $(\mathrm{C} 16: 0)$ and stearate $(\mathrm{C} 18: 0)$ decreased significantly in cells transfected with miR-24 mimic $(P<0.05)$; however, C16:0 increased in cells containing the miR-24 inhibitor $(P<0.05)$.

\section{miR-24 Regulates Expression of Genes Related to Lipid Metabolism in GMEC}

Real-time qPCR results revealed that, relative to the control, ectopic overexpression of miR-24 strongly upregulated the expression of GPAM $(2.09$ fold; $P<$ 0.01), AGPAT6 (2.06 fold; $P<0.01$ ), PLIN2 (1.54 fold; $P<0.01), L P L$ (1.28 fold; $P<0.05), S C D 1$ (1.34 fold; $P<0.05$ ), CD36 (1.45 fold; $P<0.01$ ), and SREBF1 (1.65 fold; $P<0.01)$, but downregulated FASN (0.50 fold; $P<0.01), A C A C A$ (0.71 fold; $P<0.05)$, ACSS2 (0.70 fold; $P<0.05$ ), INSIG1 (0.60 fold; $P<0.01$ ), and PNPLA2 (0.37 fold; $P<0.01$; Figure 3A). In contrast, cells transfected with miR-24 inhibitor displayed marked downregulation of AGPAT6 (0.74 fold; $P<0.05)$, SCD1 (0.56 fold; $P<0.01), P L I N 2(0.47$ fold; $P<0.01), L P L$ (0.52 fold; $P<0.01), C D 36(0.78$ fold; $P<0.05$ ), and SREBF1 (0.54 fold; $P<0.01$ ), but upregulated FASN (1.89 fold; $P<0.01$ ), ACACA (1.46 fold; $P<0.01$ ), and INSIG1 (1.68 fold; $P<0.01$; Figure $3 \mathrm{~B}$ ). Furthermore, the protein level of FASN in GMEC containing the miR-24 mimic and inhibitor was consistent with the mRNA expression response (Figure $3 \mathrm{C})$.

As described in Figure $4 \mathrm{~A}$ and $4 \mathrm{~B}$, we found a strong correlation between miR-24 and miR-27a expression ( $\mathrm{r}=0.64 ; P=0.001)$, but not between miR-24 and miR-103 expression $(\mathrm{r}=-0.412 ; P=0.045)$. Overexpression of miR-24 downregulated miR-27a expression (3.13 fold; $P<0.01$ ), but no significant relationship was found between miR-24 and miR-103 (1.24 fold; $P$ $>0.05$; Figure $4 \mathrm{C}$ ).

\section{miR-24 Suppresses FASN Activity in GMEC}

The GMEC with the miR-24 mimic had lower FASN activity ( 0.61 fold; $P<0.01$; Figure $5 \mathrm{~A}$ ), whereas the GMEC with the miR-24 inhibitor had greater FASN
Table 4. Effects of microRNA-24 (miRNA-24) mimic and inhibitor on FA composition in goat mammary epithelial cells

\begin{tabular}{|c|c|c|}
\hline $\mathrm{FA}^{1}$ & $\begin{array}{l}\text { MiR-24 } \\
\text { mimic }\end{array}$ & $\begin{array}{c}\text { Negative } \\
\text { control (NC) }\end{array}$ \\
\hline $\begin{array}{l}\text { C16:0 (\%) } \\
\text { C16:1 (\%) } \\
\text { C18:0 (\%) } \\
\text { C18:1 (\%) } \\
\text { C18:2 (\%) } \\
\text { SFA (\%) } \\
\text { UFA }{ }^{2}(\%) \\
\text { UFA/SFA }\end{array}$ & $\begin{array}{c}25.49 \pm 1.24^{\mathrm{b}} \\
9.32 \pm 1.18^{\mathrm{A}} \\
3.64 \pm 0.43^{\mathrm{B}} \\
59.55 \pm 2.32^{\mathrm{A}} \\
2.00 \pm 0.14^{\mathrm{a}} \\
26.13 \\
73.87 \\
2.83 \\
\text { MiR-24 } \\
\text { inhibitor }\end{array}$ & $\begin{array}{c}31.59 \pm 1.20^{\mathrm{a}} \\
2.10 \pm 0.24^{\mathrm{B}} \\
15.04 \pm 0.95^{\mathrm{A}} \\
50.03 \pm 2.78^{\mathrm{B}} \\
1.24 \pm 0.18^{\mathrm{b}} \\
46.63 \\
53.37 \\
1.14 \\
\text { MiRNA } \\
\text { inhibitor NC }\end{array}$ \\
\hline $\begin{array}{l}\text { C16:0 (\%) } \\
\text { C16:1 (\%) } \\
\text { C18:0 (\%) } \\
\text { C18:1 (\%) } \\
\text { C18:2 (\%) } \\
\text { SFA (\%) } \\
\text { UFA }^{2}(\%) \\
\text { UFA/SFA }\end{array}$ & $\begin{array}{c}30.21 \pm 0.79^{\mathrm{a}} \\
3.28 \pm 0.15^{\mathrm{b}} \\
13.50 \pm 0.42 \\
51.72 \pm 0.69 \\
1.29 \pm 0.19^{\mathrm{b}} \\
43.71 \\
56.29 \\
1.29\end{array}$ & $\begin{aligned} & 27.85 \pm 0.53^{\mathrm{b}} \\
& 4.43 \pm 0.21^{\mathrm{a}} \\
& 12.86 \pm 0.31 \\
& 53.01 \pm 0.56 \\
& 1.85 \pm 0.11^{\mathrm{a}} \\
& 40.71 \\
& 59.29 \\
& 1.46\end{aligned}$ \\
\hline
\end{tabular}

${ }^{\mathrm{a}, \mathrm{b}}$ Means in a row with different superscripts differ at $P<0.05$.

${ }^{\mathrm{A}, \mathrm{B}}$ Means in a row with different superscripts differ at $P<0.01$.

${ }^{1}$ Relative FA composition is calculated as percentages relative to the total of these FA identified. Difference was determined with Tukey's test. All experiments were performed in duplicate and repeated 3 times $(\mathrm{n}=6)$.

${ }^{2} \mathrm{UFA}=$ unsaturated fatty acids.

activity $(1.85$ fold; $P<0.01)$ compared with the control (Figure 5B).

\section{miR-24 Specifically Inhibits FASN Expression}

Luciferase reporter assay revealed that the miR-24 mimic decreased the relative luciferase activity (0.59 fold; $P<0.01$ ) of the reporter containing the wild-type $3^{\prime} \mathrm{UTR}$ of FASN. In contrast, the miR-24 inhibitor increased luciferase activity by 1.62 fold $(P<0.01)$; however, the miR-24 mimic and inhibitor had no effect on the relative luciferase activity of the reporter containing the mutated $3^{\prime} \mathrm{UTR}$ of FASN (Figure 5D). These data demonstrated that miR-24 interacts directly with the predicted binding site of the FASN mRNA in GMEC.

\section{DISCUSSION}

Several candidate miRNA play important roles in the biology of the lactating goat mammary gland $(\mathrm{Li}$ et al., 2012a,b). For example, miR-27a and miR-103 expression levels were associated with lactating stages being higher in mid lactation than the dry period (Lin et al., 2013b,c). To investigate the role of miR-24, we first demonstrated that miR-24 is expressed in goat 
mammary tissue, with expression level being highest at peak lactation. The enrichment of miR-24 at the peak lactation stage may be a reflection of its physiological role in the regulation of milk component synthesis or development of the adult mammary gland.
Previous research in GMEC demonstrated that miR27a could suppress TAG accumulation and miR-103 could increase milk fat synthesis, TAG accumulation, and lipid droplet formation in GMEC (Lin et al., 2013a,b). The fact that the lipid accumulation and
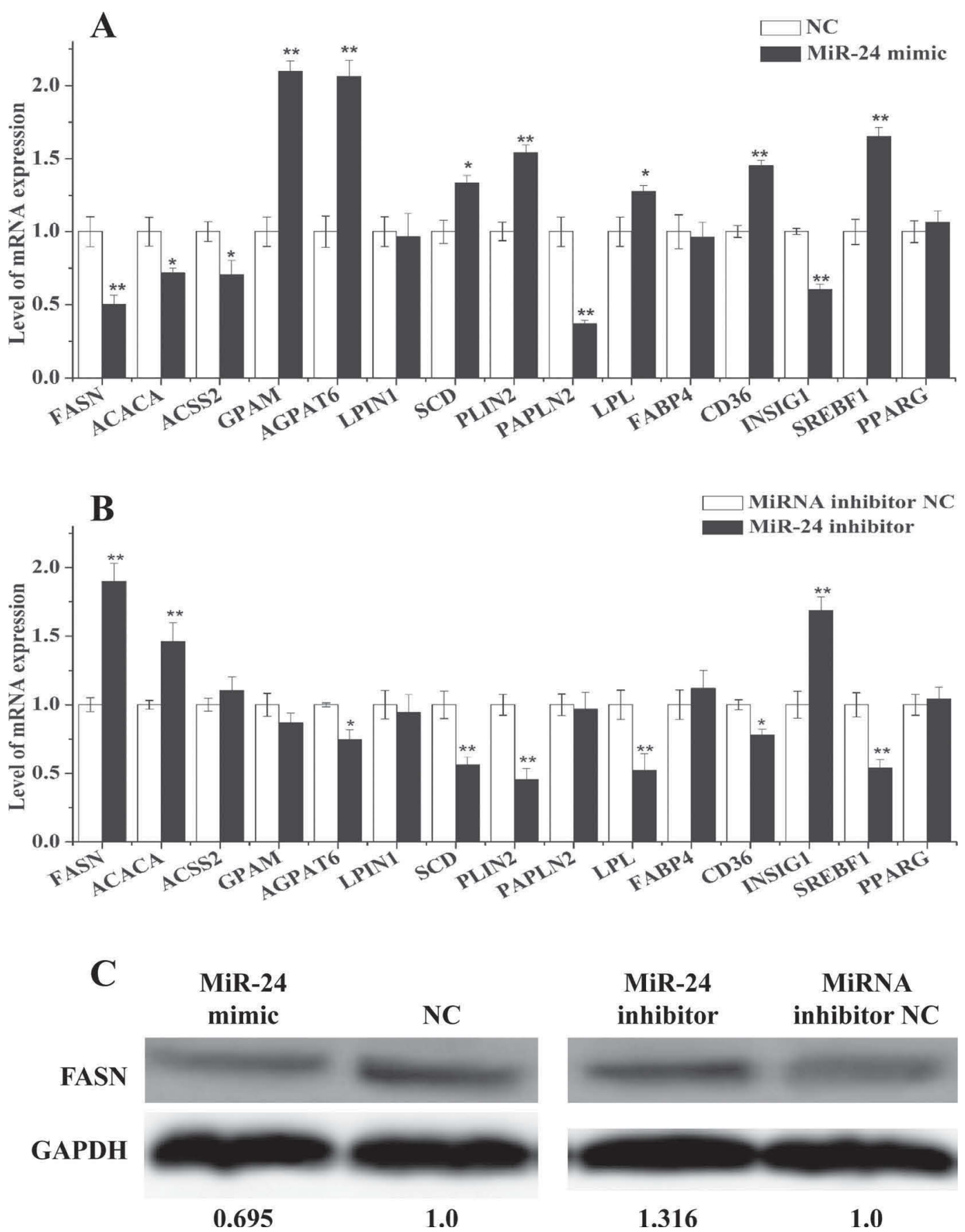

Figure 3. Expression of lipid metabolism-related genes. (A and B) Goat mammary epithelial cells were transfected with microRNA-24 (miR24) mimic or inhibitor at $48 \mathrm{~h}$ post-transfection, and FASN, ACACA, ACSS2, GPAM, AGPAT6, LPIN1, SCD1, PLIN2, PNPLA2, LPL, FABP4, CD36, INSIG1, SREBF1, and PPARG expression levels were quantified by quantitative real-time PCR $(\mathrm{n}=6)$. (C) Western blot analysis of FASN expression in the miR-24 mimic or inhibitor treatment experiments (one representative replicate). All experiments were performed in duplicate and repeated 3 times $(\mathrm{n}=6)$. Values are presented as means $\pm \mathrm{SEM} ;{ }^{*} P<0.05, * * P<0.01$. 
A

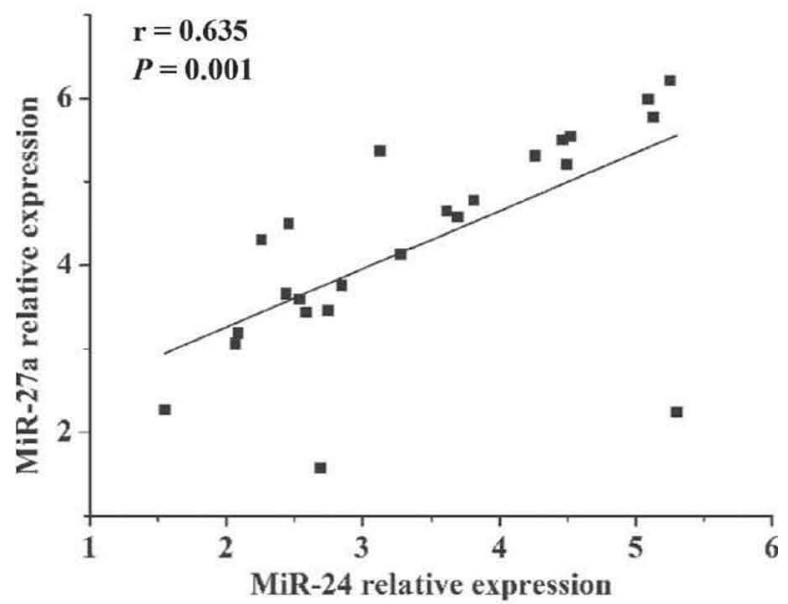

B

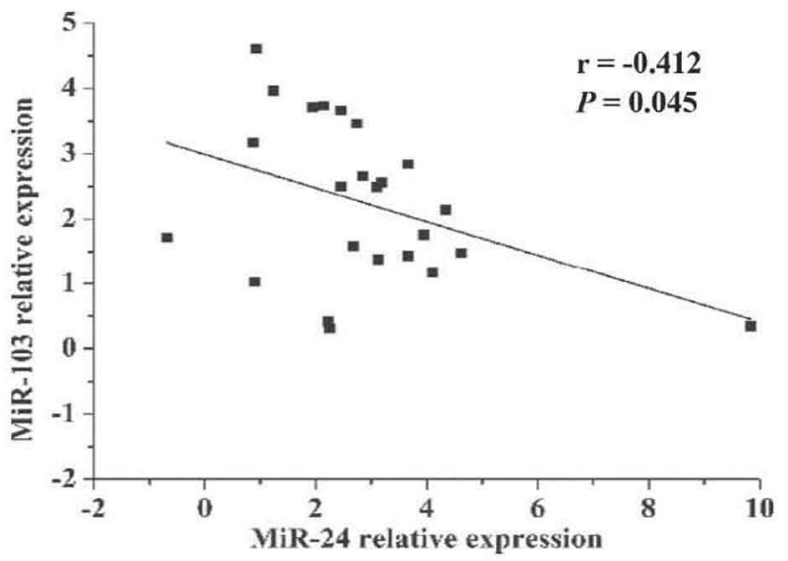

C

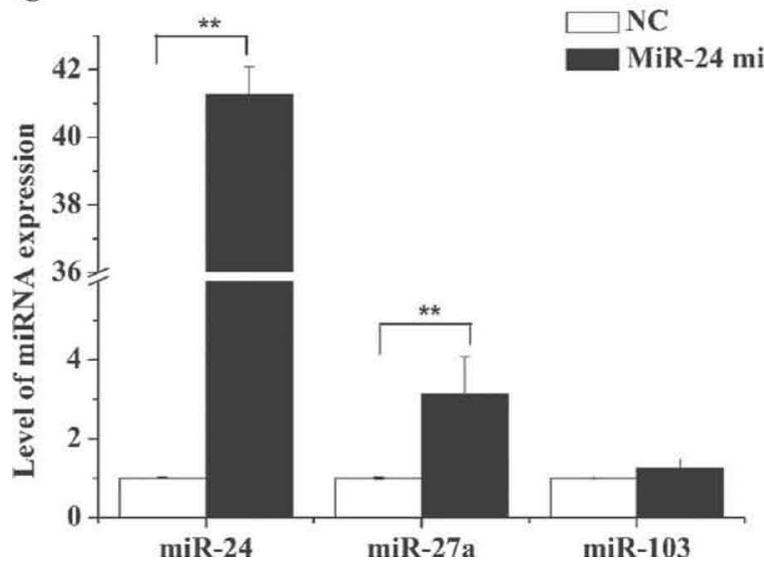

Figure 4. Correlation between microRNA (miR) expression in mammary gland of lactating goats and expression of miR in goat mammary epithelial cells transfected with miR-24 mimic. (A and $\mathrm{B}$ ) The expression of miR-24, miR-27a, and miR-103 were measured in each of 24 goats (midlactation) and repeated 3 times; (A) Ccorrelation between miR-24 and miR-27a; (B) correlation between miR-24 and miR-103. (C) Expression level of miR-24, miR-27a, and miR-103 was determined in GMEC at $48 \mathrm{~h}$ post-transfection(with experiments were performed in sextuplicate and repeated 3 times $(n=18)$. The expression of miR was normalized to internal control ( $5 \mathrm{~S}$ rRNA). Values are presented as means $+\mathrm{SEM} ;{ }^{*} P<0.05,{ }^{* *} P<0.01$.
TAG content were significantly altered by miR-24 in our study was consistent with the reported effect of miR-103 in GMEC (Lin et al., 2013b). However, the average miR-24 expression change in mammary tissue between the lactation and dry period was $\sim 1.96$-fold upregulation, which is modest compared with the $\sim 40$ fold upregulation detected in GMEC with the overexpression of miR-24. More importantly, overexpression of miR-24 only induced a 1.74-fold change in TAG. Such discrepancy in response could be partly explained by the lack of exogenous availability of 16:0 and 18:0 for TAG synthesis, as reported in previous in vitro studies (Waters and Ntambi, 1996; Zhang et al., 2006). Although data from in vitro studies cannot be directly extrapolated to the in vivo response, the link between miR-24 and TAG synthesis appears to be biologically relevant.

The inhibition of $F A S N$ expression and greater lipid accumulation detected in the present study with miR24 are similar to data from HepG2 cells and primary hepatocytes in which miR-107 induced lipid accumulation by posttranscriptional negative regulation by FASN (Bhatia et al., 2014). In contrast, these data are inconsistent with the reported inhibition of FASN in study utilizing small hairpin RNA (Zhu et al., 2015). The contrasting results might be due to multiple regulatory roles of miR-24, which is supported in part by the fact that it also altered expression of other genes in the lipid synthesis pathway (e.g., INSIG1, PNPLA2, and CD36). The changes detected for other genes are highly suggestive that miR-24 can induce lipid accumulation in GMEC partly via recycling of FA derived from breakdown of phospholipids or from extracellular uptake. In addition, because a previous study reported that FASN is regulated by SREBF1 (Li et al., 2015), the finding that miR-24 decreased the expression of $F A S N$ but increased $S R E B F 1$ suggests a feedback regulatory pathway may exist among miR-24, SREBF1, and FASN (Figure 6). As a terminal enzyme complex for de novo FA synthesis, FASN undoubtedly is subject to regulation by various mechanism including changes in gene expression.

Both FABP4 and INSIG1 are targets of miR-24 in humans and mice (Kang et al., 2013; Ng et al., 2014). We confirmed that miR-24 targets INSIG1 in GMEC using RT-qPCR and a Luciferase reporter assay (data not shown), which is in agreement with miR-24 targeting INSIG1 in mouse HepG2 cells (Ng et al., 2014). The fact that miR-24 had no significant effect on the $F A B P 4$ mRNA expression agrees with previous data in 3T3-L1 adipocytes (Kang et al., 2013). The current study also revealed that miR-24 could directly target the $3^{\prime} \mathrm{UTR}$ of FASN directly. 
A

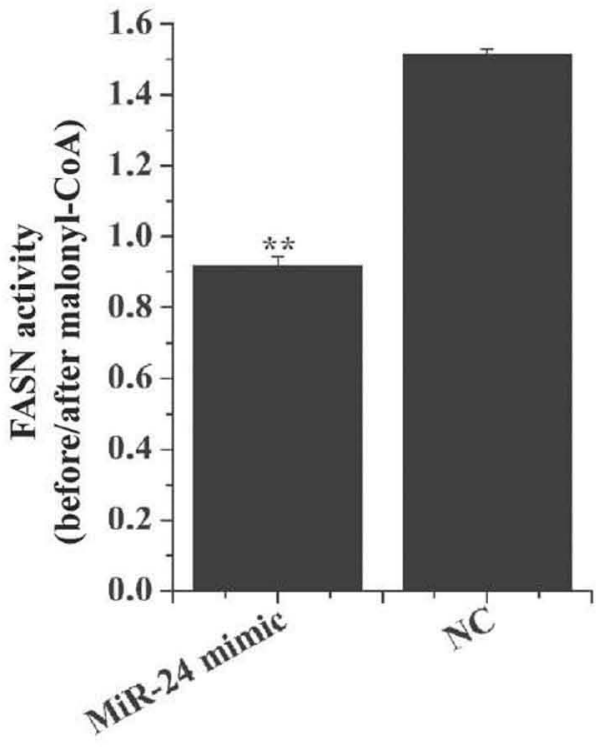

B

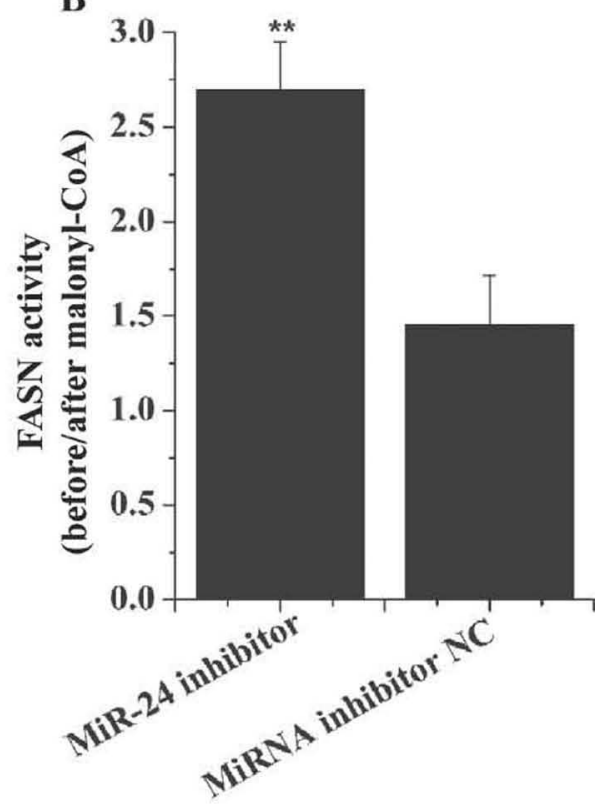

C

Bta-miR-24 3' GACAAGGACGACUUGACUCGGU 5'

Site: Position 7805-7811 of 3'UTR of goat FASN 5' ...CTGTGAAGAGTCGGCTGAGCCGCTAGCCG....3'

Bta FASN 5 '...CTGTGAAGAGTCGGCTGAGCCGCCACTAG...3

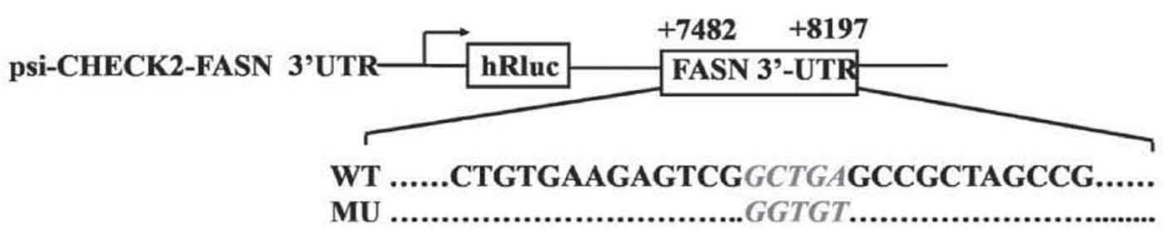

D

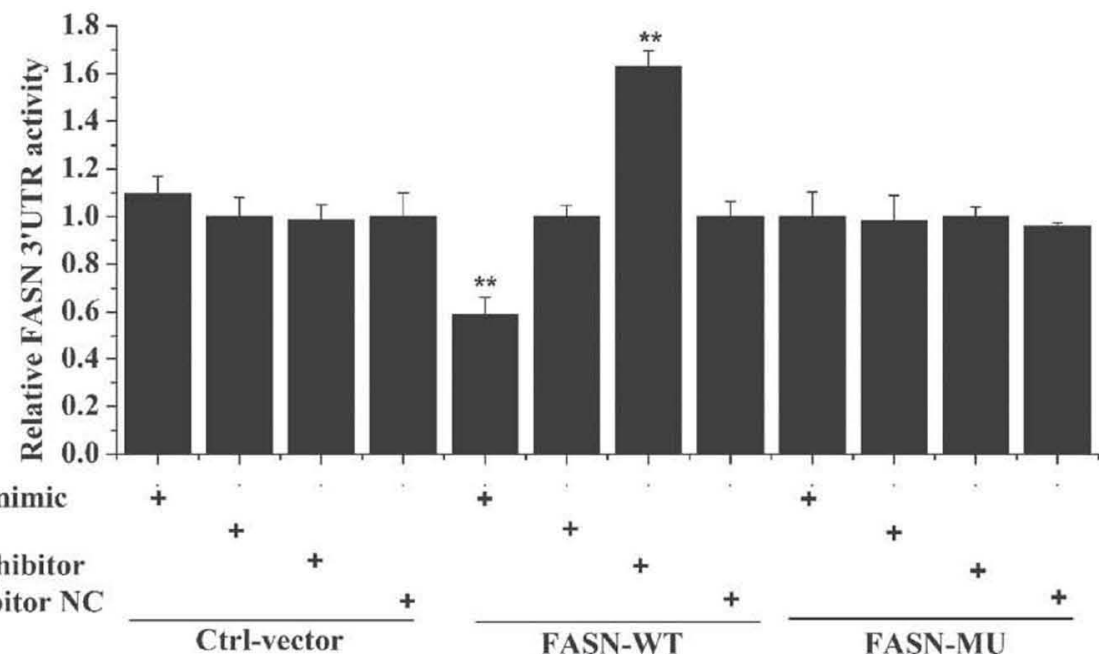

Figure 5. MicroRNA-24 (miR-24) targets FASN. Regulation of FASN activity by miR-24 mimic (A) and inhibitor (B). (C) MiR-24 site in $F A S N 3^{\prime}$ untranslated regions (UTR) and the construction of the luciferase (Luc) expression vector fused to the FASN $3^{\prime} \mathrm{UTR}$. Bta = bovine; $\mathrm{WT}=$ Luc reporter vector with the WT FASN 3'UTR (7,482 to 8,197 bp); MU = Luc reporter vector with the mutation at miR-24 site in FASN 3'UTR. (D) Induction or suppression of Luc activity with the WT or MU of the FASN 3'UTR by miR-24 mimic or inhibitor. Goat mammary epithelial cells were transfected with miR-24 mimic, inhibitor, the respective controls, and WT and MU. The Luc activity was measured at 48 $\mathrm{h}$ post-transfection. All experiments were performed in duplicate and repeated 3 times $(\mathrm{n}=6)$. Values are presented as means \pm SEM; ${ }^{*} P<$ $0.05,{ }^{*} P<0.01 . \mathrm{NC}=$ negative control; Ctrl $=$ control. 


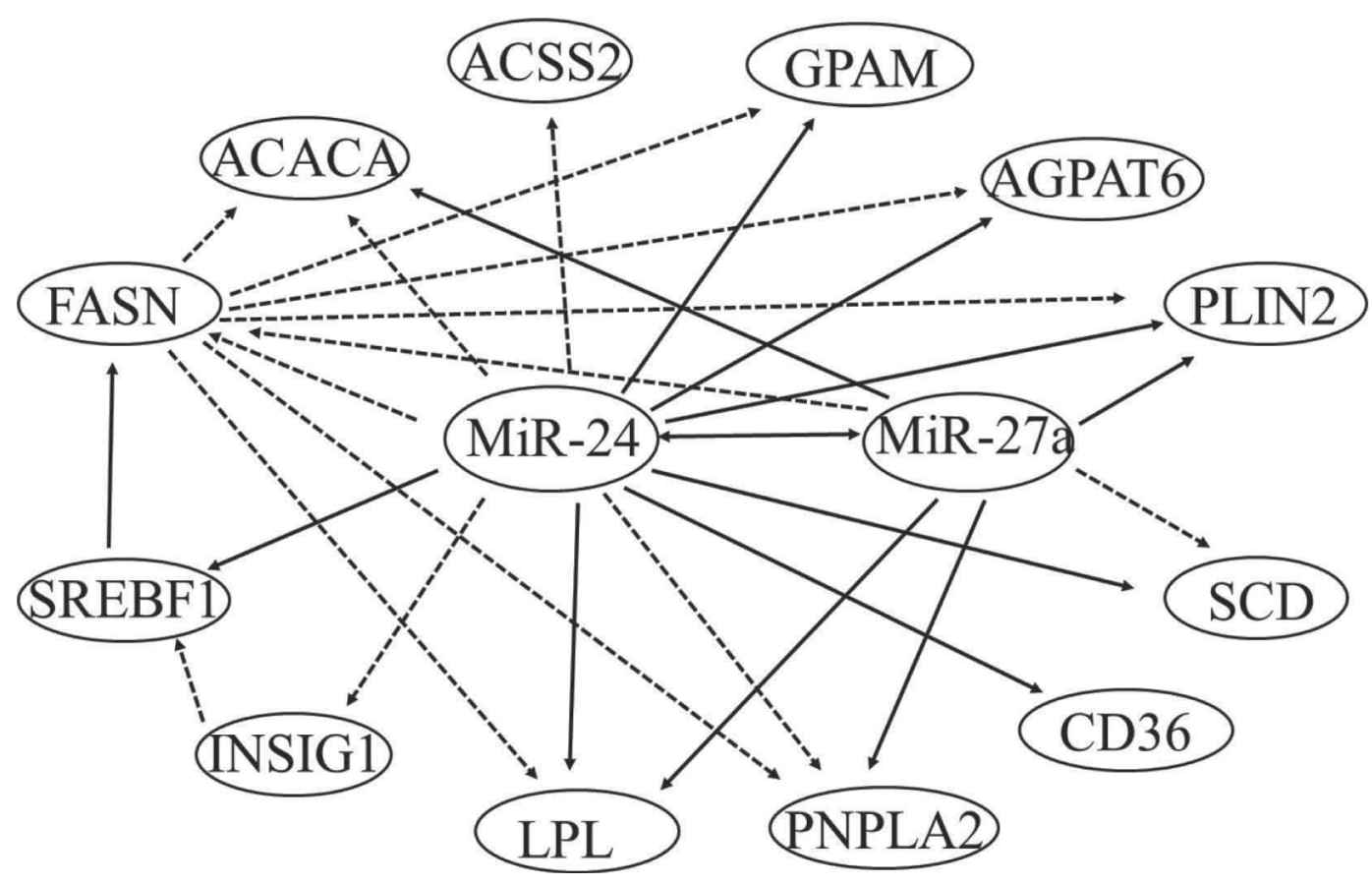

Figure 6. Gene networks related to lipid metabolism driven by microRNA in goat mammary epithelial cells. Dashed lines indicate the suppression and solid lines indicate activation.

As key transcription factors involved in lipid synthesis in bovine mammary gland, SREBF1 and PPARG can regulate the expression of the same genes, including FASN (Shi et al., 2013b; Li et al., 2015). To maintain intracellular homeostasis, the lower synthesis of de novo FA when miR-24 was overexpressed could have induced the expression of some lipid metabolism mRNA, an idea supported by the upregulation of SREBF1 (but not $P P A R G$ ) when miR-24 was overexpressed. This specific response suggested that $S R E B F 1$, but not $P P A R G$, is the major effector of miR-24 in GMEC, and this is supported by a previous study reporting that upstream transcription factors, such as $P P A R G$ and SREBF1, have different effects on downstream genes (Duplus et al., 2000).

From previous studies and our research, miR-27a, miR-103, and miR-24 are all expressed in GMEC and may interact with each other to regulate FA synthesis and metabolism (Lin et al., 2013a,b). The current study revealed a strong positive relationship between the expression level of miR-24 and miR-27a in goat mammary gland tissue, which is consistent with a previous study reporting that in human the miR-23a-miR27a-miR-24-2 cluster is transcribed by PolII (Lee et al., 2004). The correlation in the expression of miR-24 and miR-27a was confirmed in GMEC by the fact that miR-24 upregulated miR-27a expression; however, little correlation was observed between miR-24 and miR-
103, which agrees with the fact that miR-24 did not alter the expression of miR-103 in GMEC. Based on the significant effects of miR-24, miR-27a, and miR103 on the expression of the same gene (i.e., DGAT1, $S C D$, and PLIN2; Figure 3; Lin et al., 2013a,b), we speculated that the changes in FA synthesis in GMEC may have been related to the existence of co-regulation among various miRNA and target genes, underscoring the importance of molecular synergism.

The fact that ectopic expression of miR-24 led to marked upregulation of SCD expression and increased the unsaturated FA concentration is consistent with the function of SCD protein, which is to catalyze the conversion of $\mathrm{C} 16: 0$ and $\mathrm{C} 18: 0$ to $\mathrm{C} 16: 1$ and C18:1. (Miyazakia and Ntambi, 2003). Besides the control of unsaturated FA synthesis at the level of SCD, other factors [such as AGPAT6 or diacylglycerol acyltransferase 1 (DGAT1) mRNA and protein expression] may exist that in coordination with the desaturation process affects the cellular FA composition. Both DGAT1 and AGPAT6 are key components of the overall pathway leading to synthesis of milk lipid droplets and exert an effect on milk fat yield and composition (Schennink et al., 2007, 2008; Littlejohn et al., 2014). In the present study, miR-24 had a significant role in regulating AGPAT6 mRNA expression and, although we did not measure the expression of DGAT1, the mechanism leading to an overall increase in unsaturated FA synthesis by miR-24 
overexpression likely involves changes in expression of $S C D$ and other genes, or possibly increases the activity of encoded enzymes. Our data highlight the role of miR-24 in regulating the synthesis of unsaturated FA in GMEC and suggest that it might be a crucial target for regulating the composition of unsaturated $\mathrm{FA}$ in goat milk by nutritional means. Further studies are necessary to uncover the detailed mechanisms.

\section{CONCLUSIONS}

We identified miR-24 as a key player in TAG accumulation and unsaturated FA concentration in GMEC. The FASN gene is a novel direct target that links miR-24 with a potential role in control of lipid metabolism in ruminant mammary cells. In light of the results presented herein, miR-24 may potentially play a role in milk production and synthesis of beneficial milk components in dairy ruminants.

\section{ACKNOWLEDGMENTS}

This research was jointly supported by the National Natural Science Foundation of China (No. 31372281; Beijing, China), the Special Fund for Agro-scientific Research in the Public Interest (No. 201103038; Beijing, China), and the Transgenic New Species Breeding Program of China (No. 2014ZX08009-051B; Beijing, China).

\section{REFERENCES}

Adlakha, Y. K., and N. Saini. 2011. MicroRNA-128 downregulates Bax and induces apoptosis in human embryonic kidney cells. Cell. Mol. Life Sci. 68:1415-1428.

Bartel, D. P. 2004. MicroRNAs: Genomics, biogenesis, mechanism, and function. Cell 116:281-297.

Bartholomew, S. R., E. H. Bell, T. Summerfield, L. C. Newman, E. L. Miller, B. Patterson, Z. P. Niday, W. E. Ackerman, and J. T. Tansey. 2012. Distinct cellular pools of perilipin 5 point to roles in lipid trafficking. Biochim. Biophys. Acta 1821:268-278.

Bhatia, H., G. Verma, and M. Datta. 2014. miR-107 orchestrates ER stress induction and lipid accumulation by post-transcriptional regulation of fatty acid synthase in hepatocytes. Biochim. Biophys. Acta 1839:334-343.

Bionaz, M., and J. J. Loor. 2007. Identification of reference genes for quantitative real-time PCR in the bovine mammary gland during the lactation cycle. Physiol. Genomics 29:312-319.

Bionaz, M., and J. J. Loor. 2008. Gene networks driving bovine milk fat synthesis during the lactation cycle. BMC Genomics 9:366.

Bonnet, M., L. Bernard, S. Bes, and C. Leroux. 2013. Selection of reference genes for quantitative real-time PCR normalisation in adipose tissue, muscle, liver and mammary gland from ruminants. Animal 7:1344-1353.

Chen, J. F., Y. Tao, J. Li, Z. Deng, Z. Yan, X. Xiao, and D. Z. Wang. 2010. MicroRNA-1 and microRNA-206 regulate skeletal muscle satellite cell proliferation and differentiation by repressing Pax7. J. Cell Biol. 190:867-879.

Chuang, H.-Y., Y.-F. Chang, and J.-J. Hwang. 2011. Antitumor effect of orlistat, a fatty acid synthase inhibitor, is via activation of caspase-3 on human colorectal carcinoma-bearing animal. Biomed. Pharmacother. 65:286-292.

Coleman, R. A. 2004. Enzymes of triacylglycerol synthesis and their regulation. Prog. Lipid Res. 43:134-176.

Duplus, E., M. Glorian, and C. Forest. 2000. Fatty acid regulation of gene transcription. J. Biol. Chem. 275:30749-30752.

Fernández-Hernando, C., Y. Suárez, K. J. Rayner, and K. J. Moore. 2011. MicroRNAs in lipid metabolism. Curr. Opin. Lipidol. 22:8692.

Gay, I., A. Cavender, D. Peto, Z. Sun, A. Speer, H. Cao, and B. A. Amendt. 2014. Differentiation of human dental stem cells reveals a role for microRNA-218. J. Periodontal Res. 49:110-120.

Gu, Z., S. Eleswarapu, and H. Jiang. 2007. Identification and characterization of microRNAs from the bovine adipose tissue and mammary gland. FEBS Lett. 581:981-988.

Hansen, H. O., I. Grunnet, and J. Knudsen. 1984. Triacylglycerol synthesis in goat mammary gland. The effect of ATP, Mg2+ and glycerol 3-phosphate on the esterification of fatty acids synthesized de novo. Biochem. J. 220:513-519.

Juarez, M., and M. Ramos. 1986. Physico-chemical characteristics of goat's milk as distinct from those of cow's milk. Int. Dairy. Fed. 202:54-67.

Kadegowda, A. K. G., M. Bionaz, L. S. Piperova, R. A. Erdman, and J. J. Loor. 2009. Peroxisome proliferator-activated receptor- $\gamma$ activation and long-chain fatty acids alter lipogenic gene networks in bovine mammary epithelial cells to various extents. J. Dairy Sci. 92:4276-4289.

Kang, Y., S. Hengbo, L. Jun, L. Jun, Z. Wangsheng, T. Huibin, and S. Huaiping. 2015. PPARG modulated lipid accumulation in dairy GMEC via regulation of ADRP gene. J. Cell. Biochem. 116:192201

Kang, M., L. M. Yan, Y. M. Li, W. Y. Zhang, H. Wang, A. Z. Tang, and H. S. Ou. 2013. Inhibitory effect of microRNA-24 on fatty acid-binding protein expression on 3T3-L1 adipocyte differentiation. Genet. Mol. Res. 12:5267-5277.

Kang, K., X. Zhang, H. Liu, Z. Wang, J. Zhong, Z. Huang, X. Peng, Y. Zeng, Y. Wang, Y. Yang, J. Luo, and D. Gou. 2012. A novel real-time PCR assay of microRNAs using S-Poly (T), a specific oligo $(\mathrm{dT})$ reverse transcription primer with excellent sensitivity and specificity. PLoS ONE 7:e48536.

Lee, Y., M. Kim, J. Han, K.-H. Yeom, S. Lee, S. Baek, and V. N. Kim. 2004. MicroRNA genes are transcribed by RNA polymerase II. EMBO J. 23:4051-4060.

Li, J., J. Luo, H. Xu, M. Wang, J. Zhu, H. Shi, A. B. Haile, H. Wang, and Y. Sun. 2015. Fatty acid synthase promoter: Characterization and transcriptional regulation by sterol regulatory element binding protein-1 in goat mammary epithelial cells. Gene 561:157-164.

Li, Z., X. Lan, W. Guo, J. Sun, Y. Huang, J. Wang, T. Huang, C. Lei, X. Fang, and H. Chen. 2012a. Comparative transcriptome profiling of dairy goat microRNAs from dry period and peak lactation mammary gland tissues. PLoS ONE 7:e52388.

Li, Z., H. Liu, X. Jin, L. Lo, and J. Liu. 2012b. Expression profiles of microRNAs from lactating and non-lactating bovine mammary glands and identification of miRNA related to lactation. BMC Genomics 13:731

Lin, X., J. Luo, L. Zhang, W. Wang, and D. Gou. 2013b. MiR-103 controls milk fat accumulation in goat (Capra hircus) mammary gland during lactation. PLoS ONE 8:e79258.

Lin, X.-Z., J. Luo, L.-p. Zhang, W. Wang, H.-b. Shi, and J.-j. Zhu. 2013a. miR-27a suppresses triglyceride accumulation and affects gene mRNA expression associated with fat metabolism in dairy goat mammary gland epithelial cells. Gene 521:15-23.

Lin, X., J. Luo, L. Zhang, and J. Zhu. 2013c. MicroRNAs synergistically regulate milk fat synthesis in mammary gland epithelial cells of dairy goats. Gene Expr. 16:1-13.

Littlejohn, M. D., K. Tiplady, T. Lopdell, T. A. Law, A. Scott, C. Harland, R. Sherlock, K. Henty, and V. Obolonkin. 2014. Expression variants of the lipogenic AGPAT6 gene affect diverse milk composition phenotypes in Bos taurus. PLoS ONE 9:e85757. 
Miyazaki, M., and J. M. Ntambi. 2003. Role of stearoyl-coenzyme A desaturase in lipid metabolism. Prostaglandins Leukotr. Essent. Fatty Acids 68:113-121.

Ng, R., H. Wu, H. Xiao, X. Chen, H. Willenbring, C. J. Steer, and G. Song. 2014. Inhibition of microRNA-24 expression in liver prevents hepatic lipid accumulation and hyperlipidemia. Hepatology 60:554-564.

Peterson, D. G., E. A. Matitashvili, and D. E. Bauman. 2004. The inhibitory effect of trans-10, cis-12 CLA on lipid synthesis in bovine mammary epithelial cells involves reduced proteolytic activation of the transcription factor SREBP-1. J. Nutr. 134:2523-2527.

Schennink, A., J. M. Heck, H. Bovenhuis, M. H. Visker, H. J. van Valenberg, and J. A. van Arendonk. 2008. Milk fatty acid unsaturation: Genetic parameters and effects of stearoyl-CoA desaturase (SCD1) and acyl CoA:diacylglycerol acyltransferase 1 (DGAT1). J. Dairy Sci. 91:2135-2143.

Schennink, A., W. M. Stoop, M. H. Visker, J. M. Heck, H. Bovenhuis, J. J. van der Poel, H. J. van Valenberg, and J. A. van Arendonk. 2007. DGAT1 underlies large genetic variation in milk-fat composition of dairy cows. Anim. Genet. 38:467-473.

Shi, H., J. Luo, J. Zhu, J. Li, Y. Sun, X. Lin, L. Zhang, D. Yao, and H. Shi. 2013a. PPAR $\gamma$ regulates genes involved in triacylglycerol synthesis and secretion in mammary gland epithelial cells of dairy goats. PPAR Res. 2013:310948.

Shi, H., H. Shi, J. Luo, W. Wang, A. B. Haile, H. Xu, and J. Li. 2014. Establishment and characterization of a dairy goat mammary epithelial cell line with human telomerase (hT-MECs). Anim. Sci. J. 85:735-743.

Shi, H. B., J. Luo, D. W. Yao, J. J. Zhu, H. F. Xu, H. P. Shi, and J. J. Loor. 2013b. Peroxisome proliferator-activated receptor- $\gamma$ stimulates the synthesis of monounsaturated fatty acids in dairy goat mammary epithelial cells via the control of stearoyl-coenzyme A desaturase. J. Dairy Sci. 96:7844-7853.

Shirasaki, T., M. Honda, T. Shimakami, R. Horii, T. Yamashita, Y. Sakai, A. Sakai, H. Okada, R. Watanabe, S. Murakami, M. Yi, S.
M. Lemon, and S. Kaneko. 2013. MicroRNA-27a regulates lipid metabolism and inhibits hepatitis $\mathrm{C}$ virus replication in human hepatoma cells. J. Virol. 87:5270-5286.

Vimalraj, S., and N. Selvamurugan. 2014. MicroRNAs expression and their regulatory networks during mesenchymal stem cells differentiation toward osteoblasts. Int. J. Biol. Macromol. 66:194-202.

Wang, M., S. Moisa, M. J. Khan, J. Wang, D. Bu, and J. J. Loor. 2012 MicroRNA expression patterns in the bovine mammary gland are affected by stage of lactation. J. Dairy Sci. 95:6529-6535.

Wang, Z., J. Luo, and W. Wang. 2010. Characterization and culture of isolated primary dairy goat mammary gland epithelial cells. Sheng Wu Gong Cheng Xue Bao 26:1123-1127.

Waters, K. M., and J. M. Ntambi. 1996. Polyunsaturated fatty acids inhibit hepatic stearoyl-CoA desaturase-1 gene in diabetic mice. Lipids 31:S33-S36.

Yang, Y., W. Sun, R. Wang, C. Lei, R. Zhou, Z. Tang, and K. Li. 2015. Wnt antagonist, secreted frizzled-related protein 1 is involved in prenatal skeletal muscle development and is a target of miRNA-1/206 in pigs. BMC Mol. Biol. 16:4.

Zhang, S.-F., C.-Z. Ma, J.-C. Zhu, J.-P. Wang, Y.-C. Wen, and T.-D. Fu. 2006. Genetic Analysis of oil content in Brassica napus L. using mixed model of major gene and polygene. Yi Chuan Xue Bao $33: 171-180$

Zhu, J. J., J. Luo, Y. T. Sun, H. B. Shi, J. Li, M. Wu, K. Yu, A. B Haile, and J. J. Loor. 2015. Short communication: Effect of inhibition of fatty acid synthase on triglyceride accumulation and effect on lipid metabolism genes in goat mammary epithelial cells. J. Dairy Sci. 98:3485-3491

Zhu, J. J., J. Luo, W. Wang, K. Yu, H. B. Wang, H. B. Shi, Y. T. Sun, X. Z. Lin, and J. Li. 2014. Inhibition of FASN reduces the synthesis of medium-chain fatty acids in goat mammary gland. Animal 8:1469-1478. 